\title{
QUANTITATIVE ESTIMATION OF CHANGES IN THE SYSTEM PIPELINE — WELL, IN CASE OF EMERGENCY SITUATION OCCURRENCE DURING HORIZONTAL DIRECTIONAL DRILLING
}

\author{
- - оропов, - • оном рев, С. - оропов, • • оропов \\ V. S. Toropov, T. G. Ponomareva., S. Yu. Toropov, E. S. Toropov \\ оябрьский институт нефти и г з -фили $\Omega$, г. оябрьск \\ юменский индустри льный университет, г. юмень \\ лючевые слов : горизонт льное н пр вленное бурение; трубопровод; буровой р створ;
в рийн я ситу ция; грунт; скв жин \\ Key words: Horizontal directional drilling; pipeline; mud; emergency; ground; well
}

енденции в бестр ншейном строительстве, очевидно, будут приводить к возникновению зн чительного числ в рийных ситу ций р зного род [1]. н стоящее время это вызыв ется не только ошибк ми строительств, но и проектиров ния, т кже отсутствием междун родной системы единых ст нд ртов оборудов ния [2].

ех низм вз имодействия трубопровод со стенкой скв жины во время с мого ответственного эт п , прот скив ния, ок зыв ет реш ющее влияние н величину требуемого тягового усилия и одновременно является с мым сложным элементом для исследов ния ввиду невозможности непосредственного н блюдения и количественного измерения п р метров, т кже многообр зия процессов, которые могут иметь место при р зличных обстоятельств х производств р бот.

же при отсутствии к ких-либо осложнений этот мех низм может иметь р зный $\mathrm{x}$ р ктер при р зличных в ри нт х орг низ ции процесс прот скив ния. хемы вз имодействия могут р злич ться в з висимости от свойств грунт и м тери л стенки трубы, н личия или отсутствия б лл стировки водой, т кже от м рки и к честв бурового $\mathrm{p}$ створ [3]. чественно изменить всю к ртину вз имодействия может применение к кого-либо вспомог тельного оборудов ния [4].

ля нешт тной ситу ции х р ктерно появление дополнительных ф кторов, вносящих свои коррективы в мех низм т кого вз имодействия. иболее зн чительные это потеря циркуляции бурового р створ и обрушение свод скв жины.

ри шт тной ситу ции, в первую очередь, формируется пр вильный ствол скв жины в процессе пионерного бурения. к к грунтовый м ссив н ходится в н пряженном состоянии от собственного вес, и грунт в м ссиве уплотнен под действием этой силы, то бурение скв жины вызыв ет п дение н пряжения в грунте, н ходящемся в непосредственной близости от пробуренной скв жины. то обстоятельство вызыв ет р зуплотнение грунт и выпир ние его в скв жину н некоторую величину. о есть 
при бурении скв жины д нного ди метр необходимо учитыв ть уменьшение ее ди метр 3 счет р зуплотнения грунт .

ля оценки уменьшения ди метр необходимо р ссмотреть среднее д вление м ссив грунт н стенку скв жины, пробуренной в грунтовом м ссиве. од средним будем поним ть д вление от собственной м ссы грунт по горизонт льной плоскости, проходящей через центр скв жины.

этом случ е д вление грунт [2]

$$
q_{c p}=\gamma_{2 p} h_{c p}
$$

где $\gamma_{2 p}$ - объемный вес грунт в естественном состоянии; $h_{c p}-\mathrm{p}$ сстояние от дневной поверхности до оси скв жины.

ким способом мы будем определять д вление грунт до глубины бурения $h_{c p}<h_{c \beta}, \mathrm{H}$ которой не обр зуется свод естественного $\mathrm{p}$ вновесия. вод естественного р вновесия н чин ет обр зовыв ться с глубины

$$
h_{c B}=\frac{D_{s}}{\operatorname{tg}^{2}\left(45^{\circ}-\frac{\varphi}{2}\right) \operatorname{tg} \varphi},
$$

где $D_{s}$ - ди метр скв жины; $\varphi$ - угол внутреннего трения грунт .

ысот свод естественного р вновесия

$$
b_{c B}=\frac{D_{s}\left[1+\operatorname{tg}^{2}\left(45^{\circ}-\frac{\varphi}{2}\right)\right]}{2 \operatorname{tg} \varphi} .
$$

ри достижении $h_{c p}$ величины $h_{c в}$ д вление м ссив грунт н стенку скв жины будем определять к к

$$
q_{c p}=\gamma_{c p} b_{c B} .
$$

о скв жин , в процессе бурения и прот скив ния в нее трубопровод , полностью 3 полнен буровым р створом, который, в свою очередь, созд ет д вление н стенку скв жины изнутри. вление бурового р створ н глубине $h_{c p}$ будет

$$
q_{\sigma}=\gamma_{\sigma} h_{c p}
$$

где $\gamma_{6}$ - объемный вес бурового р створ .

ро н лизируем д вление, ок зыв емое н стенку скв жины со стороны грунтового м ссив и бурового р створ . ля этого используем профиль скв жины, пробуренной по некоторому р диусу $R_{c \kappa в}$ и длиной в пл не $L_{c \kappa в}$.

оместим н ч ло координ т в точке вход трубопровод в скв жину. огд ур внением кривой, описыв ющей скв жину, будет ур внение окружности р диус $R, \mathrm{H}-$ ч ло координ т которой р спол г ется в точке $\left(\frac{L}{2} ; \sqrt{R^{2}-\frac{L^{2}}{4}}\right)$ :

$$
\left(x-\frac{L}{2}\right)^{2}+\left(y-\sqrt{R^{2}-\frac{L^{2}}{4}}\right)^{2}=R^{2}
$$

или

$$
y^{2}-2 \sqrt{R^{2}-\frac{L^{2}}{4}} y+x^{2}-x L=0
$$

ешением этого ур внения будет

$$
y_{1,2}=\sqrt{R^{2}-\frac{L^{2}}{4}} \pm \sqrt{R^{2}-\frac{L^{2}}{4}-x^{2}+x L} .
$$


орни ур внения будут д в ть н м з глубление оси скв жины в д нной точке.

лее, обр щ я вним ние н то, что превышение з глубления скв жины глубины обр зов ния свод естественного р вновесия обусловлив ет изменение д вления н стенку скв жины со стороны грунтового м ссив , построим гр фики изменения д влении грунт и бурового р створ н стенку скв жины.

рис. 1 изобр жены эпюры д вления н стенку скв жины в з висимости от величины $з$ глубления со стороны грунтового м ссив и бурового р створ . ссив грунт и буровой р створ д вят н стенку скв жины с р зных сторон, поэтому эпюры этих д влений имеют противоположные зн ки.

невн я поверхность изобр жен пунктирной линией. гр фике (3) существуют две обл сти $H_{1}$ и $H_{2}$, в которых д вление от грунтового м ссив резко п д ет из-з появления свод естественного р вновесия. всем протяжении скв жины, ниже глубины обр зов ния свод естественного р вновесия, д вление грунтового м ссив постоянно.

вление бурового р створ изнутри скв жины изменяется пропорцион льно глубине скв жины.

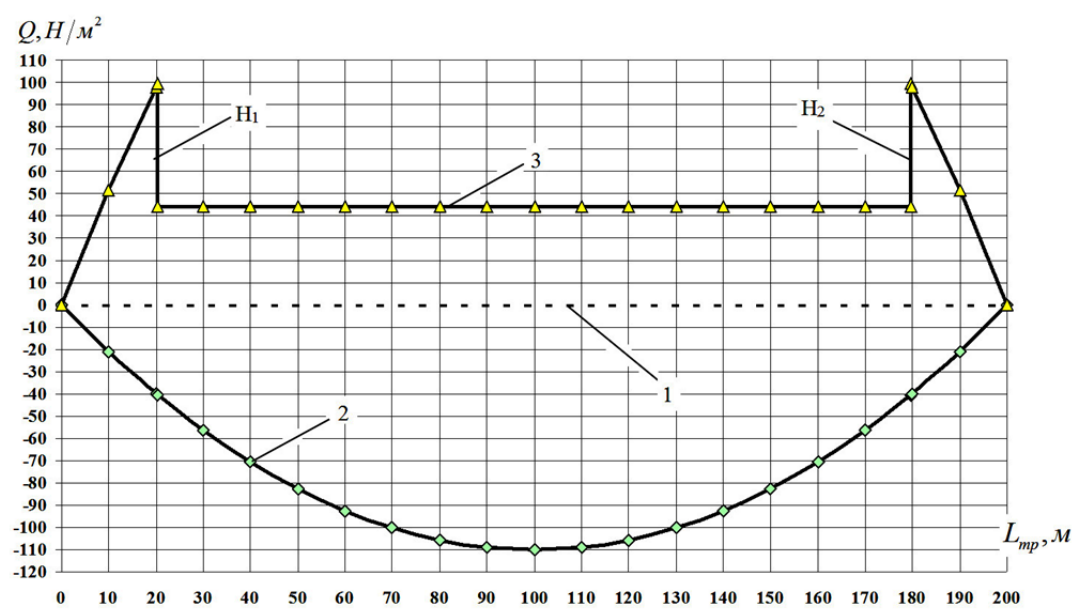

ис. 1. спределениед влениян стенку скв жины со стороны грунтовогом ссив (3) и бурового р створ (2), пунктиром пок $з$ н дневн я поверхность (1)

рис. 2 пок з но сумм рное д вление н стенку скв жины. з приведенных з висимостей следует, что уч сток скв жины, н ходящийся ниже глубины обр зов ния свод естественного р вновесия грунт, поп д ет в отриц тельную зону эпюры.

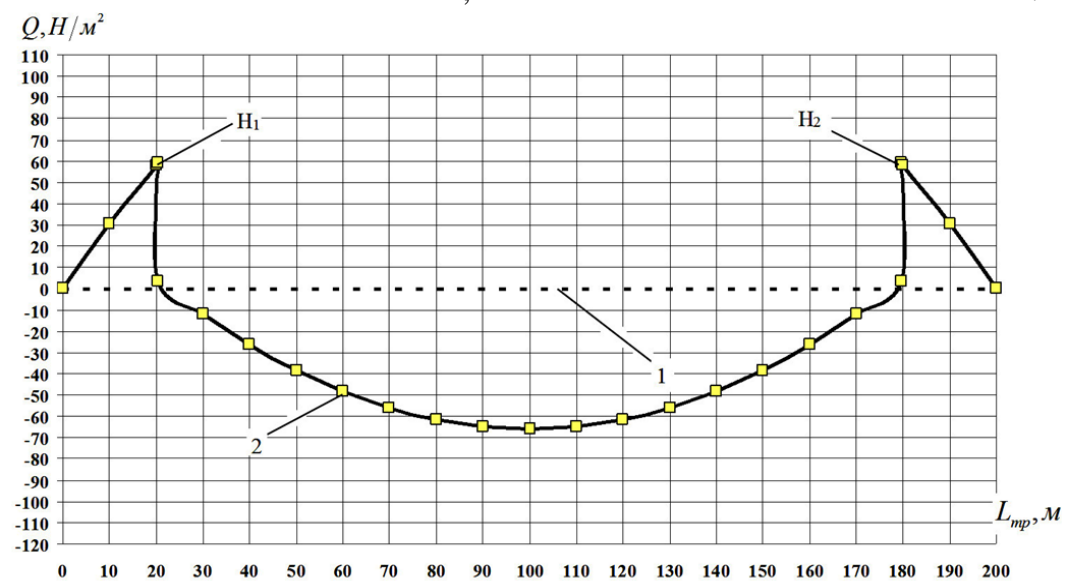

ис. 2. спределение сумм рного д вления н стенку скв жины со стороны грунтового м ссив и бурового р створ (2), пунктиром пок з н дневн я поверхность (1) 
о есть н этом уч стке д вление бурового р створ превыш ет д вление грунтового м ссив . ледов тельно, выпучив ние грунт внутрь пробуренной скв жины не может иметь место н этом уч стке.

уч стк х вход и выход н блюд ется ин я к ртин . десь из-з того, что н стенку скв жины д вит не только свод естественного р вновесия, весь грунт, н ходящийся выше, д вление грунт превыш ет д вление бурового р створ . н чит, именно н уч стк х вход и выход может н блюд ться р зуплотнение грунт внутрь скв жины. ыпучив ние грунт будет происходить пропорцион льно р знице д влений грунт и бурового р створ .

ким обр зом, в шт тной ситу ции, когд буровой р створ удержив ет стенки скв жины от обрушения, p зуплотнение грунт внутрь скв жины может происходить только н коротких уч стк х н входе и выходе скв жины, являющихся в этом смысле потенци льно оп сными.

ри потере циркуляции бурового р створ в потенци льно оп сную зону поп д ет весь ствол скв жины. тому же прот скив емый трубопровод теряет нулевую пл вучесть и входит в конт кт с нижней обр зующей скв жины.

еоретически при иде льно гл дкой и недеформируемой поверхности трубопровод и скв жины ширин полосы конт кт будет р вн нулю, поскольку конт кт происходит лишь в точке соприкосновения трубопровод и скв жины.

р ктически конт ктируемые поверхности обл д ют определенной шерохов тостью, кроме того, н р зных уч стк х имеет место просед ние трубопровод под собственным весом и под действием изгиб ющих усилий. оэтому будем р ссм трив ть случ и к с ния трубопроводом стенки скв жины и случ й деформ ции ее трубопроводом к к один и тот же случ й с р зными количественными х р ктеристик ми, именно просед нием трубопровод относительно стенки скв жины.

ссмотрим деформ цию трубопроводом нижней обр зующей скв жины (д нный p счет будет спр ведлив для отклонения трубопровод от оси скв жины в любую сторону). ким обр зом, трубопровод, деформируя нижнюю обр зующую скв жины, з глубляется н некоторую величину $h$ (рис. 3), котор я определяет ширину полосы конт кт трубопровод и скв жины $L$. рис. 3 стенк скв жины и внешняя стенк трубы изобр жены к к две окружности, ди метр ми соответственно $D_{s}$ и $d_{e}$ (р диусы $R_{s}$ и $r_{e}$ ), нижние точки которых смещены друг относительно друг н величину 3 глубления трубопровод $h$. ч ло координ т помещено в нижнюю точку окружности р диусом $R_{s}$.

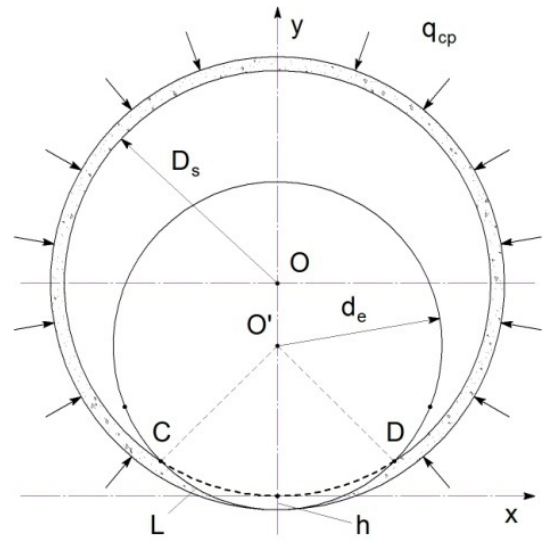

ис. 3. хем конт кт трубопровод со стенкой скв жины в отсутствии бурового р створ

ля определения ширины зоны конт кт трубопровод и стенки скв жины $L$ н йдем координ ты пересечения окружностей в точк х $C$ и $D$. ля этого з пишем ур внения этих окружностей.

ля скв жины

$$
x^{2}+\left(y-R_{s}\right)^{2}=R_{s}^{2} .
$$


ля трубы

$$
x^{2}+\left(y-r_{e}+h\right)^{2}=r_{e}^{2} .
$$

ри решении д нной системы ур внений получим

$$
\begin{aligned}
& y=\frac{h(2 r-h)}{2\left(R_{s}-r_{e}+h\right)}, \\
& x=\sqrt{R_{s}^{2}-\left(y-R_{s}\right)^{2}} .
\end{aligned}
$$

рименим формулы геометрии н плоскости и выр зим ширину зоны конт кт трубопровод и стенки скв жины

$$
L=2 r_{e} \arcsin \frac{x}{r_{e}}
$$

то есть

$$
L=2 r_{e} \arcsin \frac{\sqrt{R_{s}^{2}-\left(\frac{h\left(2 r_{e}-h\right)}{2\left(R_{s}-r_{e}+h\right)}-R_{s}^{2}\right)}}{r_{e}} .
$$

ким обр зом, площ дь поверхности $S_{2 p}$ конт кт уч стк трубопровод длиной $L_{m p}$ с грунтом определится к к

$$
S_{\text {гp }}=L_{m p} \cdot L .
$$

лощ дь конт кт уч стк трубопровод с буровым р створом

$$
S_{\sigma}=L_{m p}\left(2 \pi r_{e}-L\right) .
$$

рис. 4 изобр жен схем смятия трубопроводом стенки грунтовой скв жины.

процессе вз имодействия трубопровод со стенкой скв жины, при з глублении трубы н величину $h$, стенк скв жины смин ется, и грунт деформируется. десь через $L^{*}$ обозн чен ширин полосы деформ ции скв жины.

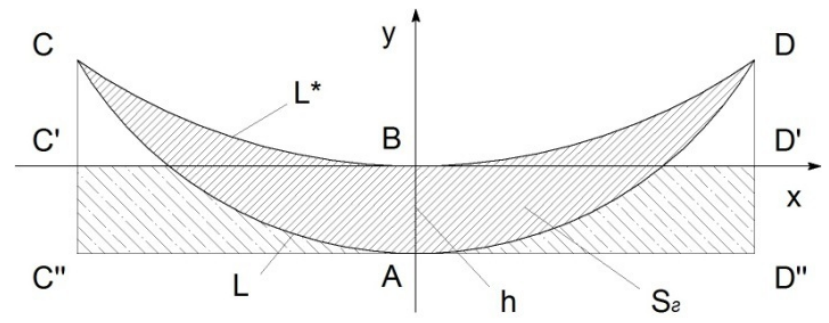

ис. 4. хем вз имодействия скв жины и стенки трубопровод :

$h$-величин з глубления трубопровод, $L$ - ширин зоны конт кт трубопровод $c$

грунтом, $S_{2}$ - площ, дь грунт, деформируемого трубопроводом

реобр зуем зону деформ ции грунт $A C B L$ площ дью $S_{2}$ в зону деформ ции $C$ ' $' D$ ' $D$ '. ереносим точки $C$ и $D$ перпендикулярно вниз до пересечения с осью $O x$. олуч ем прямоугольное сечение (глубин $h$, длин поверхности конт кт $\left.b=C^{\prime} D^{\prime}\right)$, которое более удобно использов ть в р счет х. роме того, выбор именно т кого сечения позволяет н м говорить о том, что р счет ведется с некоторым 3 п сом. ким обр зом, будем р ссм трив ть деформ цию плоской поверхности н величину $h$ по линии длиной 


$$
b_{\text {кон }}=2 r_{e} \sin \frac{L}{2 r_{e}} .
$$

соответствии с ней ре кция грунт основ ния в к ждой точке подошвы 6 лки прямо пропорцион льн ос дке этой точки [5]:

$$
P_{2 p}=k_{s} h,
$$

где $P_{2 p}-$ ре кция грунт ; $h$ - величин ос дки трубопровод ; $k_{s}-$ коэффициент постели.

огд сил отпор грунт, действующ я н погонный метр трубопровод , будет

$$
F_{\text {гр }}=k_{s} h b_{\text {кон }} .
$$

пределять коэффициент постели будем в соответствии с з висимостями, изложенными в [6], полученными н основ нии проведения шт мповых испыт ний.

ормул уссинеск для определения модуля деформ ции грунт в н турных условиях связыв ет коэффициент постели с модулем деформ ции грунт для кв др тного шт мп и коэффициент бокового р сширения грунт $v_{\text {гp }}=0,25$

$$
E_{\imath p}=55 k_{s} .
$$

ким обр зом, для определения ос дки трубопровод в грунте необходимо 3 д ть модуль деформ ции грунт .

ри возникновении в рийной ситу ции резко увеличив ется тяговое усилие, необходимое для д льнейшего движения трубопровод внутри скв жины. помощью приведенных выше подходов имеется возможность количественно оценить величину дополнительного сопротивления перемещения трубы по смятой стенке буровой скв жины при отсутствии в ней норм льной циркуляции бурового р створ и, к к следствие, потери прот скив емым трубопроводом нулевой пл вучести.

ля опис ния полной к ртины вз имодействия необходимо дополнительно учесть явление присос, т кже ф ктор возможного н личия воды во внутренней полости трубопровод , помещенной туд в целях его б лл стировки.

\footnotetext{
писок литер турь

1. оропов . ., оропов . еменков . ., ерошт нов . . сложнения при сооружении переходов трубопроводов методом горизонт льного н пр вленного бурения // ерритория « 37.

2. рейдбурд . . оль подземных инженерных коммуник ций при комплексном освоении подземного простр нств // троительство. ехнологии. рг низ ция. - 2016. - № 46. - . 34-36.

3. ирьянов .. оропов .. оропов пределение з висимостей силы сопротивления движению трубопровод в искривленной скв жине от физических п р метров и реологической модели применяемого бурового р створ // ефтяное озяйство. - 2015. - № 8. - . 48-50.

4. оропов . ., оропов . ., одорожников . ., ерошт нов . . рименение дополнительного оборудов ния в технологии горизонт льного н пр вленного бурения // орный информ ционно- н литический бюллетень (н учно-технический журн л) - 2014 - № S4 - 207-214.

5. лм тов . . ех ник грунтов, основ ния и фунд менты. - $\quad . \quad$ тройизд т, 1981. $-319 \mathrm{c.}$

6. осте ., нглер . ех ник грунтов. р ктический курс. - .: тройизд т, 1981. 455 с.

7. ород вкин . . ех ник грунтов в трубопроводном строительстве. - $\therefore$ едр , 1986. - 224 с.

ведения об втор $x$

оропов л димир ергеевич, к. иент к федры « р нспорт и технологии нефтег зового комплекс», оябрьский институт нефти и г з - фили $л$, г. оябрьск, тел. 8(3496)428389,e-mail: 264301@mail.ru

оном рев тьян еоргиевн, к. доцент, доцент к федры «р нспорт углеводородных ресурсов», юменский индустри льный университет, г. юмень, тел. 8(3452)201931, e-mail:zemenkov@tsogu.ru

оропов ергей рвевич, д. т. н., профессор $\kappa$ федры « нспорт углеводородных ресурсов», юменский индустри льный университет, тел.

Information about the authors

Toropov V. S., Candidate of Science in Engineering, associate professor of the chair «Transport and technologies of petroleum complex», Noyabrsk Institute of Oil and Gas, affiliate of the Industrial University of Tyumen, phone: 8(3496)428389, e-mail:264301@mail.ru

Ponomareva T. G., Candidate of Science in Engineering, associate professor of the chair «Transport of hydrocarbon resources», Industrial University of Tyumen, phone: 8(3452)201931, e-mail: zemenkov@tsogu.ru

Toropov S. Yu., Doctor of Engineering, professor of the chair "Transport of hydrocarbon re sources», Industrial University of Tyumen, phone:
} 


\section{8(3452)201931,e-mail:89222639334@mail.ru}

оропов вгений ергеевич, $к$. . н., доцент $\kappa$ федры « $р$ нспорт и технология нефтег зового комплекс », оябрьский институт нефти и 23 - фили $л$, г. оябрьск, тел 8(3496)428389,e-mail: toropov_e_s@mail.ru
8(3452)201931, e-mail:89222639334@mail.ru

Toropov E. S., Candidate of Science in Engineering, associate professor of the chair «Transport and technologies of petroleum complex», Noyabrsk Institute of Oil and Gas, affiliate of the Industrial University of Tyumen, phone: 8(3496)428389, e-mail: toropov_e_s@mail.ru 